\title{
Conjunctival melanoma: a review of conceptual and treatment advances
}

This article was published in the following Dove Press journal:

Clinical Ophthalmology

12 March 2013

Number of times this article has been viewed

\section{Li-Anne Lim' \\ Michele C Madigan ${ }^{1,2}$ \\ R Max Conway'}

'Save Sight Institute, Clinical Ophthalmology, The University of Sydney, Sydney, New South Wales, Australia; ${ }^{2} \mathrm{School}$ of Optometry and Vision Science, The University of New South Wales, Sydney, New South Wales, Australia
Correspondence: R Max Conway Sydney Eye Hospital and Ocular Oncology Centre, Save Sight Institute, The University of Sydney, GPO Box 4337, Sydney, NSW 2006, Australia Email drmaxconway@gmail.com
Abstract: The aim of this study was to review the available literature and identify recent advances in the classification and management of conjunctival melanoma (CM) for clinicians working in this field. English-based articles were identified using the MEDLINE ${ }^{\circledR}$ database, and additional cited works not detected in the initial search were also obtained. Articles were assessed according to the Australian National Health and Medical Research Council levels of evidence criteria. Review of the literature indicated that the current classification and management of CM is predominantly based upon primarily nonrandomized, single-institution, retrospective case series. While these studies provide the basis for the recent seventh edition of the tumor node metastasis staging classification, this classification more accurately reflects the current knowledge of prognostic factors for CM. Application of this revised classification system together with prospective trials will provide the opportunity for future consistent and comparable data collection across centers, and it will improve the quality of evidence upon which current classification and management of CM is based. Furthermore, the high risk of local recurrence with current standard management suggests that adjuvant therapy, particularly mitomycin $\mathrm{C}$ and/or brachytherapy, may improve outcomes regardless of clinical staging. Finally, the use of sentinel lymph node biopsy may have significant benefit for a select group of CM patients.

Keywords: adjuvant therapy, melanoma in situ, mitomycin C, metastases

\section{Introduction}

Invasive melanoma of the conjunctiva is a rare but sight- and life-threatening condition. It accounts for $2 \%-5 \%$ of ocular malignancies ${ }^{1}$ and $5 \%-7 \%$ of all primary ocular melanoma. ${ }^{2,3}$ Its incidence is increasing, ${ }^{4-7}$ a trend similar to that seen in cutaneous melanoma. ${ }^{6}$ Despite progress and therapeutic advances in the management of conjunctival melanoma (CM),${ }^{8}$ local recurrence rates are as high as $62 \%,{ }^{9}$ mortality ranging from $18 \%$ to $44 \% .{ }^{10-15}$ No prospective multicenter trials have been conducted, and most of what is known is based upon a number of population-based, cross-sectional studies $^{2,5-7,12,13,16-19}$ and single-center, retrospective case series. ${ }^{9-11,14,15,20-29}$ There is a lack of consistency and consensus regarding the classification, grading, staging, and treatment of pigmented ocular surface lesions, making it difficult to draw meaningful comparisons between published studies. As a result, the supporting evidence for clinical and histological prognostic factors and survival has produced variable results and has affected the management of pigmented lesions in different centers over time.

The aim of this study was to review the available literature and identify recent advances in the classification and management of CM for clinicians working in this field. The review identified advances in three main areas: (1) classification and staging 
of pigmented conjunctival lesions, (2) clinical management of $\mathrm{CM}$ and the use of adjuvant therapy, and (3) sentinel lymph node biopsy (SLNB).

\section{Literature search}

The MEDLINE ${ }^{\circledR}$ database was searched for all relevant articles written in English between 1950 and 2011. Primary search terms and their synonyms were used singly or in combination, including "conjunctiva," "melanoma," "pigmented," "malignant," "neoplasm," "primary acquired melanosis" (PAM), "cryotherapy," "brachytherapy," "radiotherapy," and "mitomycin C" (MMC). Pertinent peerreviewed English-language articles from the primary search made on the basis of content and scope were then reviewed. Hand and manual searches were also performed for articles referenced in bibliographies that were not initially retrieved by the search, as well as in specific areas in which information was lacking. Articles for each subtopic were assessed according to the Australian National Health and Medical Research Council levels of evidence criteria. ${ }^{30}$

\section{Results and discussion Classification and staging of pigmented conjunctival lesions}

Many classifications for pigmented lesions of the conjunctiva have been proposed, a major criticism being the way in which classifications relate to prognosis and affect subsequent management; under-treatment or over-treatment sometimes leading to unnecessary morbidity. The clinical and pathological term "primary acquired melanosis" has been widely used for many years. ${ }^{31}$ Historically, the histological criteria of PAM have been divided into two groups: with and without atypia. ${ }^{32}$ PAM without atypia has been used to describe lesions in which there is an overproduction of melanin both with and without melanocytic hyperplasia; melanocytes are normal, with no atypical features, and are confined to the basilar epithelium. In contrast, PAM with atypia has been used to describe lesions in which there are atypical melanocytes with a specific growth pattern. Four types of atypical melanocytes may be seen in the conjunctiva: (1) small polyhedral cells, (2) spindle cells, (3) large melanocytes with complex arborizing dendrites, and (4) round epithelioid cells. A mixture of cells may be seen in some lesions. Five different growth patterns may be seen: (1) basilar hyperplasia, in which proliferating melanocytes are confined to the basilar epithelium, (2) basilar nests, which consist of clusters of melanocytes that push against the overlying epithelium without invasion, (3) intraepithelial nests, (4) individual cell invasion into the epithelium, and (5) melanoma in situ, in which atypical melanocytes completely replace the conjunctival epithelium. ${ }^{32}$

Despite the widespread use of the PAM classification in the literature, problems with this classification have been identified, as reported by Damato and Coupland. ${ }^{33}$ First, the classification is broad and the criteria are ambiguous. The term "PAM without atypia" includes hypermelanosis, both with and without cellular proliferation, while "PAM with atypia" includes conjunctival melanocytic intraepithelial neoplasia with mild atypia, CM in situ, and secondary pagetoid spread from invasive melanoma. ${ }^{33}$ Furthermore, the grades of atypia - mild, moderate, and severe - are subjective and show poor inter- and intraobserver reproducibility. Recently a new classification system for the histological grading and staging of conjunctival melanocytic intraepithelial proliferations has been introduced, ${ }^{33}$ in an attempt to address problems with the current system; this new classification includes an objective scoring system for grading conjunctival melanocytic intraepithelial neoplasia with atypia (from 0 to 10), and evaluates the horizontal and vertical location of atypical melanocytes in CM as well as cytology. ${ }^{33}$ This system also provides a means of classifying melanoma in situ as a separate entity, similar to the classification in cutaneous melanoma. The most recent (seventh) edition of the tumor node metastasis (TNM) staging classification provides the first definition of melanoma in situ for $\mathrm{CM}$ as being confined to the epithelium and, where atypia replaces $75 \%$ of the normal epithelial thickness, with more severe cytological features including abundant cytoplasm, vesicular nuclei or prominent nucleoli, and/or the presence of intraepithelial nests of atypical cells. ${ }^{34}$ Finally, in keeping with the classification in the seventh edition of the TNM for $\mathrm{CM}$, the authors support limiting the term "primary acquired melanosis" to clinical descriptions, as suggested by Damato and Coupland ${ }^{33}$ and by Harooni et al. ${ }^{35}$

Diagnosis based on histological features alone can be difficult. In some cases, lesions may be labeled as "indeterminate" or "borderline" if pathologists are not able to reach a consensus. In these cases, immunohistochemistry may be helpful. CM cells stain for several melanoma markers, with some being more useful than others. S100 is sensitive ${ }^{36,37}$ but not specific for CM, while HMB-45 is less sensitive but more specific than S100. ${ }^{36}$ For distinguishing between benign and malignant lesions, S100 and MART-1 have been shown to not be useful, although a small study of 18 specimens found S100 A1staining did differentiate between nevi and CM, with nevi staining poorly (mean $30.6 \%$ ) compared with the strong staining (mean, $71.4 \%$ ) of CM. ${ }^{38}$ Four studies have 
shown HMB-45 to be useful in this application, ${ }^{39-42}$ although this use remains controversial. ${ }^{36} \mathrm{~A}$ study of 30 melanocytic lesions showed Wilms' tumor gene 1 protein expression to be useful in distinguishing benign and malignant lesions, with diffuse positive staining seen in $86 \%$ (six of seven) of melanomas and $86 \%$ (six of seven) of cases of PAM, compared with weak to moderate staining seen in $80 \%$ (eight of ten) of benign and $83 \%$ (five of six) of atypical nevi. Wilms' tumor gene 1 expression also decreased with maturation of the melanocytic elements in benign nevi. ${ }^{42}$ One study has also shown a higher proliferation index using $\mathrm{Ki}-67$ as a marker to convincingly separate melanomas from nevi. A comparison of positive cell counts of Ki-67 between nevi $(\mathrm{n}=12)$ and a combined group of atypical PAMs and melanomas in situ (nine atypical PAMs accompanying melanoma nodules, two melanomas in situ; $n=11$ ) using the Mann-Whitney $U$ test showed a statistically significant difference between the lesions $(P<0.001) .{ }^{40}$ S100, MART1, and HMB-45 have been shown to assist in differentiation between melanophages and melanocytes and may improve the evaluation of pagetoid spread and tumor maturation. ${ }^{43}$ In addition, more recently, Bcl-2 (an anti-apoptotic cell death protein) has been shown to be a more robust and consistent immunohistochemical marker for melanocytic tumors of the conjunctiva than S100, Melan-A, and HMB45. Diffuse positivity for Bcl-2 was seen in 94\% (116 of 123) of all cases, compared with S100 in 70\% (86 of 123), Melan-A in 81\% (100 of 123), and HMB-45 in 27\% (33 of 123) of all cases. ${ }^{42} \mathrm{Ki}-67$ has also been found to be helpful in determining biological behavior, with lesions stained positive for Ki-67 showing aggressive clinical behavior. ${ }^{43}$ The combination of both immunohistochemistry and other morphological features can provide a more comprehensive diagnosis. $^{43}$

The application of gene mutation analysis to $\mathrm{CM}$ has also not been definitive in classifying lesions. However, recent work using multiplex ligation-dependent probe amplification $^{44}$ identified a BRAF V600E mutation in approximately $50 \%$ of a small cohort of primary CMs, and more than $50 \%$ of metastatic specimens, supporting results of earlier studies. ${ }^{45-47}$ It has been proposed that the BRAF inhibitor PLX4023 (vemurafenib), specific for the V600E mutation, could be used for the treatment of CM, similar to the situation for cutaneous melanoma with BRAF V600E mutation. ${ }^{44}$

CM lesions are staged according to the TNM classification system. ${ }^{34}$ The sixth edition of the TNM staging classification for $\mathrm{CM}^{8}$ has limitations because the staging system does not correlate well with currently recognized prognostic factors for CM, as discussed by Damato and Coupland. ${ }^{33}$ The seventh edition of the TNM staging classification for $\mathrm{CM}^{34}$ (Table 1) has attempted to address these limitations, but the classification only applies to $\mathrm{CM}$ and primary acquired melanosis with atypia. Significant changes identified include the following points:

1. The inclusion of a pTis is stage, or melanoma in situ, when the tumor is limited to the epithelium. This was

Table I Pathologic tumor (T) staging (extent of disease through completion of definitive surgery) for conjunctival melanoma (CM)

\begin{tabular}{|c|c|}
\hline Pathologic stage & Stage category definition \\
\hline $\mathrm{PTX}$ & PT cannot be assessed \\
\hline рT0 & No evidence of $\mathrm{p} T$ \\
\hline \multirow[t]{12}{*}{ pTis } & Melanoma confined to the conjunctival epithelium \\
\hline & Less than or equal to one quadrant ${ }^{\mathrm{a}}$ \\
\hline & Melanoma confined to the conjunctival \\
\hline & epithelium, melanoma in situ (includes the term \\
\hline & primary acquired melanosis) \\
\hline & - Atypia replacing $>75 \%$ of normal epithelial \\
\hline & thickness \\
\hline & - Epithelioid cytology including: \\
\hline & * Abundant cytoplasm \\
\hline & * Vesicular nuclei or prominent nucleoli \\
\hline & $\begin{array}{l}\text { * And/or the presence of intraepithelial nests } \\
\text { of atypical cells. }\end{array}$ \\
\hline & $* \leq \mathrm{I}$ quadrant \\
\hline TI & CM of the bulbar conjunctiva \\
\hline \multirow[t]{2}{*}{ pTla } & $\begin{array}{l}\text { Thickness } \leq 0.5 \mathrm{~mm} \text { with invasion of the } \\
\text { substantia propria }\end{array}$ \\
\hline & $\begin{array}{l}\text { More than one but less than or equal to two } \\
\text { quadrants }^{\mathrm{a}}\end{array}$ \\
\hline \multirow[t]{2}{*}{ pTIb } & $\begin{array}{l}\text { Thickness }>0.5 \text { and } \leq 1.5 \mathrm{~mm} \text { with invasion of } \\
\text { the substantia propria }\end{array}$ \\
\hline & $\begin{array}{l}\text { More than two but less than or equal to three } \\
\text { quadrants }\end{array}$ \\
\hline \multirow[t]{2}{*}{ pTIc } & $\begin{array}{l}\text { Thickness }>1.5 \mathrm{~mm} \text { with invasion of the } \\
\text { substantia propria }\end{array}$ \\
\hline & More than three quadrants ${ }^{\mathrm{a}}$ \\
\hline $\mathrm{T} 2$ & $\begin{array}{l}\mathrm{CM} \text { of the nonbulbar conjunctiva (palpebral, } \\
\text { forniceal, caruncular) region }\end{array}$ \\
\hline $\mathrm{pT} 2 \mathrm{a}$ & $\begin{array}{l}\text { Thickness } \leq 0.5 \mathrm{~mm} \text { with invasion of the } \\
\text { substantia propria }\end{array}$ \\
\hline $\mathrm{p} T 2 \mathrm{~b}$ & $\begin{array}{l}\text { Thickness }>0.5 \text { and } \leq 1.5 \mathrm{~mm} \text { with invasion of } \\
\text { the substantia propria }\end{array}$ \\
\hline $\mathrm{p} T 2 \mathrm{c}$ & $\begin{array}{l}\text { Thickness }>1.5 \mathrm{~mm} \text { with invasion of the } \\
\text { substantia propria }\end{array}$ \\
\hline $\mathrm{pT} 3$ & $\begin{array}{l}\text { Melanoma invades the eye, eyelid, nasolacrimal } \\
\text { system, sinuses, or orbit }\end{array}$ \\
\hline pT4 & Melanoma invades the central nervous system \\
\hline
\end{tabular}

Notes: aQuadrants are defined by clock hour, starting at the limbus (eg, 3, 6, 9, 12) extending from central cornea to and beyond the eyelid margins - this will bisect the caruncle. Used with the permission of the American Joint Committee on Cancer (AJCC), Chicago, Illinois. The original source for this material is the AJCC Cancer Staging Manual, Seventh Edition (2010) published by Springer Science and Business Media LLC, http://www.springerlink.com. Edge SB, Byrd DR, Compton CC, editors. AJCC Cancer Staging Manual. 7th ed. New York, NY: Springer; 2010.34

Abbreviation: $\mathrm{PT}$, primary tumor. 
not previously specified, and the inclusion acknowledges melanoma in situ (frequently referred to as PAM with atypia) as a precursor of invasive disease. Populationbased studies show that $36 \%-71 \%$ of CMs arise from PAM lesions. ${ }^{2,5,12,13,18}$ Folberg et al, ${ }^{31}$ in a series of 41 cases of PAM with 13 years of follow-up, found that 13 of 28 lesions (46.4\%) of PAM with atypia progressed to CM. The histological pattern of tumor growth (the predominant histological pattern other than basilar hyperplasia showing $90 \%$ progression, $P=0.02$ ) and the presence of epitheliod cells ( $75 \%$ progression to $\mathrm{CM}, P=0.02$ ) were found to be the most useful predictors of progression. Both recurrences of CM lesions and PAM with atypia lesions that eventually progressed to CM were seen as progression. Similarly, Shields et al, ${ }^{48}$ in a retrospective case series of 311 eyes with conjunctival PAM without melanoma at initial presentation, found that $13 \%$ of PAM lesions with severe atypia progressed to CM.

2. A clinical description of tumor location in the T classification, the number of quadrants affected, and involvement of the caruncle. This more closely reflects National Health and Medical Research Council level IV evidence of tumor location as a poor prognostic factor for local recurrence - specifically, medial tumor location, ${ }^{33}$ nonlimbal tumors, $, 5,17,18$ and those in an "unfavorable location" at the palpebral conjunctiva, ${ }^{14,17}$ fornix, caruncle, corneal stroma, and eyelid, ${ }^{14}$ as well as poor prognostic factors for distant metastases and mortality, including nonlimbal tumors, ${ }^{10,16-18,20,24}$ tumors in an "unfavorable location,"14 palpebral conjunctiva ${ }^{49}$ and tumors involving the tarsal and forniceal regions, ${ }^{13,49}$ and caruncle. ${ }^{9,10,13,22}$ The sixth edition of the TNM staging classification of the primary tumor $^{8}$ does not reflect these data well. All nonbulbar tumors, including those at the caruncle, were categorized together as T3 tumors, while tumors invading the eyelid, globe, orbit, sinuses, or central nervous system were categorized as T4 tumors. As pointed out recently by Damato and Coupland, ${ }^{33}$ this does not reflect prognosis accurately, as it fails to recognize the poorer prognosis of tumors involving the caruncle, instead suggesting that intraocular invasion, classified in the sixth edition of the TNM staging classification ${ }^{8}$ as a T4 tumor, has a worse prognosis than caruncular involvement, a T3 tumor. There are lymphatics in the conjunctiva, ${ }^{50,51}$ although the evidence for intraocular lymphatics (specifically, choroidal lymphatics) is currently equivocal. CM involvement of the caruncle is thus more likely to lead to a worse prognosis than CM intraocular invasion, as suggested by Damato and Coupland. ${ }^{33}$ Similarly, eyelid and brain involvement both classified as T4 tumors are unlikely to have the same prognosis, the latter being more likely to be associated with a lower life expectancy. ${ }^{33}$

3. The description of local invasion and tumor thickness in the primary tumor pathology, although not mentioned in the clinical TNM classification system. ${ }^{34}$ Increasing tumor thickness is a prognostic risk factor for both regional and distant metastases and for mortality. 5,10,17,18,21 Tumor thickness may be accurately measured clinically using ultrasound biomicroscopy, as shown in a small case series, ${ }^{52}$ and may be used to guide the use of SLNB. ${ }^{53}$

4. The description of cases of synchronous PAM with atypia and CM in the definitions of histological grade. In 1985, Folberg et al, ${ }^{25}$ in their study of 131 cases from the Registry of Ophthalmic Pathology, Armed Forces Institute of Pathology, identified prognostic factors that were specific to tumors originating from PAM lesions. For these lesions, the authors found that the thickness of the patients' lesions correlated with prognosis, with increasing tumor thickness increasing mortality. Tumor depth of invasion $>0.8 \mathrm{~mm}$ was associated with a worse prognosis and greater risk of metastatic disease and mortality than thinner lesions. This association between tumor thickness and prognosis was not found when using the patients' initial biopsies. The growth pattern of the PAM component, however, was stated to be the single most sensitive histological prognostic factor, while the presence of a pagetoid growth pattern within the PAM component was found to be more sensitive in its association with mortality than tumor thickness. Other risk factors associated with mortality $(P<0.05)$ in the PAM component of the lesion include the presence of a melanoma in situ growth pattern, invasion of sclera, episclera or cornea, a paucity of small polyhedral cells in the invasive nodule, moderate to severe atypia in the PAM component, greater than five mitotic figures per ten high-power fields, and a relative lack of an inflammatory response in the invasive nodule. None of the factors studied were found to be associated with mortality in the group of melanomas without a PAM component. However, a population-based study found that the presence of PAM was not associated with increased mortality, ${ }^{5}$ while other studies identified de novo melanoma lesions without PAM to be a risk factor for mortality $(P=0.05),{ }^{24}$ and melanomas arising de novo to carry a higher risk for metastasis and mortality $(P<0.001) .{ }^{49}$ Two further referral-based studies found 
the histological or clinical origin of the tumor to be of no prognostic value. ${ }^{10,20}$

5. The description of whether a biopsy has been performed being included in the node category.

At present, no stage or prognostic grouping is currently recommended. ${ }^{34}$ There are no reliable prognostic criteria and, as a result, studies on survival predictive factors have shown variable results. Several clinical, 5,10,13,14-18,23,25,26 histological, ${ }^{10,13,21,22,29}$ management, ${ }^{14,24,25}$ and biological factors ${ }^{30}$ have been identified as poor prognostic factors; however, there have also been studies that have not supported such findings. ${ }^{5,10,13,14,21}$ As the incidence of CM is relatively low, most case series are small, with a limited follow-up period. Furthermore, it is difficult to make comparisons between studies, as patients have often been treated over a long period of time, with different modalities by different clinicians. Some series have not distinguished between patients with primary lesions and those with recurrent lesions, while different definitions of local recurrence have been used between studies. For example, Werschnik and Lommatzsch ${ }^{14}$ defined local recurrence as growth of a new lesion at the same area as the previous tumor following initial therapy, while Esmaeli et $\mathrm{al}^{15}$ defined local recurrence as any recurrent lesion on the conjunctiva (not melanoma in situ or PAM).

Of the population-based studies, Tuomaala et $\mathrm{al}^{5}$ found nonlimbal tumor location, thickness, and local recurrence to be statistically and clinically the most significant independent indicators of worse prognosis. Tuomaala et al's ${ }^{17}$ study from the same series of 85 cases in Finland is one of the largest histopathological population-based studies to find tumor location and recurrence of the primary tumor to be independent factors in predicting survival. Poor prognostic factors for CM are summarized in Table 2.

\section{Clinical management of $\mathrm{CM}$ and the use of adjuvant therapy}

The treatment of CM usually initially consists of a surgical en bloc excision biopsy to remove all macroscopic tumors. In the case of extensive lesions in which this is not possible, incisional biopsies may be performed. ${ }^{54}$ However, incisional biopsies are avoided if possible, to minimize the risk of seeding and tumor spread. A "no touch" technique is recommended, ${ }^{54}$ with the use of fresh sterile instruments at each new step of the surgical procedure, again to minimize the risk of tumor seeding. ${ }^{54,55}$ Furthermore, care should be taken to ensure minimal specimen manipulation, with the specimen spread flat and thin, and fixed to allow for accurate histopathological assessment, as any curling or distortion of the specimen may alter the diagnosis.

Local recurrence is common in $\mathrm{CM}$, with a reported incidence ranging from $36 \%$ to $62 \%{ }^{13,17}$ Surgical excision alone, without adjuvant therapy, has been shown in referral-based studies to be a prognostic factor for local relapse. ${ }^{14,23,55}$ Adjuvant intraoperative treatment is used for clinically undetectable remaining tumor cells along the surgical margins. For perilimbal tumors, Shields et $\mathrm{al}^{54}$ recommended including localized alcohol corneal epitheliectomy, although the present authors were unable to find published results of Shields et al's ${ }^{54}$ treatment regimen. Absolute alcohol, which devitalizes conjunctival cells, may also be applied to the scleral base to treat any residual tumor cells, ${ }^{54,56}$ as treatment with cryotherapy in this region carries a risk of damage to underlying structures, including the retina, and complications including uveitis, cataract formation, ciliary body shutdown with hypotony, ${ }^{56}$ and scleral melt. ${ }^{57}$ Double freeze-thaw cryotherapy used in combination with surgical excision at initial treatment has been shown to significantly reduce recurrence rates when compared with surgical excision alone $(P=0.05),{ }^{23}$ but this is of no benefit for the prevention of metastatic disease. ${ }^{23,58}$ Cryotherapy is thought to have selective sensitivity for the destruction of atypical melanocytes, and it is applied to the remaining surgical margins of exposed bulbar conjunctiva using a nitrous oxide retinal cryoprobe. ${ }^{54}$

Adjuvant therapy is usually performed only if indicated, when clinical or histological examination shows residual disease with tumor extension running deeply or adjacent to surgical margins. ${ }^{55}$ In recent years, however, some centers have started using adjuvant brachytherapy for all patients, ${ }^{26,55}$ with examinations for residual disease being regarded as unreliable, even when carried out meticulously. ${ }^{55}$

\section{Adjuvant therapy: topical MMC}

Topical MMC is not recommended for use as a primary treatment for CM, as it provides poor local control. ${ }^{59}$ In a review of six case series, 16 patients with CM were treated with MMC as a primary, intraoperative, or adjuvant therapy, with an overall recurrence rate of $43 \%$ (range $0 \%-100 \%$ ). ${ }^{59}$ Various concentrations and dosing regimens have been used between studies, with no consensus reached as to which patients should be treated, optimal MMC concentration, or the use of punctal occlusion. ${ }^{55,60}$ Although topical MMC is useful in that it allows for treatment of the entire conjunctiva, including any occult disease in the remaining tissue, ${ }^{61}$ subepithelial nests and nodular tumors have been noted to be resistant. ${ }^{61,62}$ As a result, MMC has been suggested as an alternative primary 
Table 2 Poor prognostic features of conjunctival melanoma

\begin{tabular}{|c|c|c|c|}
\hline \multirow[t]{2}{*}{ Reference } & \multicolumn{3}{|l|}{ Prognostic features } \\
\hline & Local recurrence & Regional metastases & Distant metastases and death \\
\hline Missotten et al ${ }^{18}$ & Tumor location ${ }^{\mathrm{a}}$ & Tumor thickness & Tumor location $^{\mathrm{a}}$ \\
\hline (population-based study) & & Tumor diameter & Tumor diameter \\
\hline Tuomaala et $\mathrm{al}^{5}$ & Tumor location ${ }^{\mathrm{a}}$ & - & Tumor location ${ }^{\mathrm{a}}$ \\
\hline \multirow[t]{3}{*}{ (population-based study) } & & & Tumor thickness \\
\hline & & & Tumor diameter \\
\hline & & & Local recurrence \\
\hline Tuomaala and Kivelä'6 & - & Tumor thickness & Tumor location ${ }^{\mathrm{a}}$ \\
\hline \multirow[t]{3}{*}{ (population-based study) } & & & Tumor thickness \\
\hline & & & Initial systemic metastases \\
\hline & & & (without lymph node metastases) \\
\hline Tuomaala et al ${ }^{17}$ & Tumor location ${ }^{\mathrm{a}}$ & - & Tumor location ${ }^{\mathrm{a}}$ \\
\hline \multirow[t]{3}{*}{ (population-based study) } & Absence of & & Tumor thickness \\
\hline & epithelioid cells & & Tumor diameter \\
\hline & Increasing mitotic count & & Local recurrence \\
\hline \multirow[t]{4}{*}{ Shields et $\mathrm{al}^{24}$} & Tumor location ${ }^{d}$ & - & Tumor location ${ }^{\mathrm{a}}$ \\
\hline & Technique of initial & & Initial symptom lump \\
\hline & surgery (univariate & & Tumors arising de novo without PAM \\
\hline & analysis only) & & \\
\hline Werschnik & Unfavorable location ${ }^{\mathrm{b}}$ & - & Unfavorable location ${ }^{\mathrm{b}}$ \\
\hline and Lommatzsch ${ }^{14}$ & Surgical excision alone & & Age at time of diagnosis $>55$ years \\
\hline Damato and Coupland 22 & Medial tumors & - & - \\
\hline \multirow[t]{5}{*}{ Anastassiou et $\mathrm{al}^{20}$} & Grade of pigmentation & - & Tumor location ${ }^{\mathrm{a}}$ \\
\hline & Grade of invasion & & - \\
\hline & Epithelioid and mixed cells & & \\
\hline & Incomplete surgical & & \\
\hline & resection & & \\
\hline Anastassiou et $\mathrm{al}^{29}$ & - & - & Neural crest adhesion molecule \\
\hline De Potter et $\mathrm{a}^{23}$ & Surgical excision alone & - & Local recurrence \\
\hline \multirow[t]{5}{*}{ Paridaens et al ${ }^{10}$} & - & - & Tumor location ${ }^{\mathrm{a}}$ \\
\hline & & & Tumor thickness \\
\hline & & & Tumor diameter \\
\hline & & & Pure epithelioid and mixed cell tumors \\
\hline & & & Lymphocytic invasion and inflammation \\
\hline Seregard and Kock ${ }^{13}$ & - & - & Unfavorable location ${ }^{c}$ \\
\hline \multirow[t]{4}{*}{ (population-based study) } & & & Tumor thickness \\
\hline & & & Tumor diameter \\
\hline & & & High mitotic index \\
\hline & & & Epithelioid cells \\
\hline Bobić-Radovanović & - & - & High mitotic index \\
\hline et $\mathrm{al}^{21}$ & & & Lymphocytic invasion and inflammation \\
\hline \multirow[t]{3}{*}{ Folberg et $\mathrm{a}^{25}$} & - & - & Tumor thickness in tumors with \\
\hline & & & associated PAM \\
\hline & & & Associated PAM and its features \\
\hline Esmaeli et al ${ }^{15}$ & - & - & Local recurrence \\
\hline Crawford $^{28}$ & - & - & High mitotic index \\
\hline
\end{tabular}

Notes: ${ }^{a}$ Nonepibulbar/nonlimbal; ${ }^{b}$ unfavorable location: palpebral conjunctiva, fornix, caruncle, corneal stroma, eyelid; 'unfavorable location: tarsal conjunctiva, fornix, caruncle; dpalpebral.

Abbreviation: PAM, primary acquired melanosis.

treatment for PAM with atypia and, especially, superficial, diffuse, or multifocal disease. ${ }^{61}$ Most complications following topical MMC therapy use are transient, including conjunctival injection, chemosis, and superficial punctate keratitis. ${ }^{60}$ However, these side effects have also been reported to be persistent in a series where an unusually long regimen cycle of 3 weeks was used. This retrospective review of 15 patients treated with adjuvant topical MMC 0.04\% (four times a day, for 3-week-long cycles) found that at a median follow-up of 23.8 months, 12 of 15 patients (80\%) had at 
least one complication that lasted at least 6 months, and 7 of 15 patients $(47 \%)$ had at least two complications. ${ }^{63}$ Of these patients, 4 of $15(27 \%)$ had limbal stem cell deficiency with keratopathy that failed to resolve at a median of 39.9 months. One institution advocates the use of adjuvant topical MMC for intraepithelial neoplasia based upon the results of 40 patients with previously untreated tumors. ${ }^{55}$ Treatment is combined with adjunctive brachytherapy for deep invasion at 3-4 weeks following surgical resection, which is used in place of intraoperative cryotherapy and absolute alcohol. Good local control was achieved with this treatment regimen at a median follow-up of 2.7 years, with only 6 of the 40 patients $(15 \%)$ developing local recurrences.

\section{Adjuvant therapy: radiotherapy}

Use of brachytherapy as an adjuvant therapy for all lesions following surgical excision, as well as for particular anatomical lesions, has been reported, although CM is not believed to be particularly radiosensitive. ${ }^{1}$ Local excision followed by beta-ray irradiation (strontium-90/yttrium-90) or cryotherapy has previously been recommended as the treatment of choice, based upon a retrospective review of 81 cases of CM between 1960 and $1988 .{ }^{11}$ Tumor regression without recurrence was achieved in 62 of 81 cases $(77 \%)$, with 46 of the 81 patients $(57 \%)$ treated with either primary (12 of 81 patients [15\%]) or adjuvant brachytherapy (34 of 81 patients [42\%]). Details of the different treatment groups were not outlined in the study, limiting the conclusions that can be drawn from their results. A case series of 194 patients in the Netherlands also reported significantly fewer local recurrences in patients treated with excision and adjuvant strontium-90 brachytherapy than in those treated with excision only $(P=0.008)$ or with excision and cryotherapy $(P=0.038) .{ }^{18}$ Overall survival, however, was not significantly altered. In a series of 40 previously untreated CM tumors, invasive recurrence occurred in 5 of 21 patients $(24 \%)$ who did not receive radiotherapy compared with 1 of 19 patients $(5 \%)$ who did, with this patient developing a recurrence outside the irradiated field. Based on these data, logrank analysis showed radiotherapy to significantly lower the risk of local tumor recurrence at the site of the primary tumor $(P=0.03) .{ }^{22}$ Similar results were reported in a retrospective case series of 19 patients with early-stage disease (T1a N0 M0, as per the seventh edition of the TNM staging classification $\left.{ }^{34}\right) .{ }^{26}$ All patients were treated with conservative resection and adjuvant iodine-125 plaque brachytherapy, achieving good local control with no local recurrences or metastatic disease observed at a mean follow-up of 40.1 months.
Adjuvant brachytherapy is also effective in the management of lesions at less surgically accessible sites. Good local control has been reported for use in the management of CM of the palpebral conjunctiva, the eyelid, or both (13 of 14 patients [93\%] at a median follow-up of 45 months), ${ }^{64}$ as well as for lesions with scleral or corneoscleral involvement (five of five patients [100\%] at a mean follow-up of 23.4 months). ${ }^{27}$ Adjuvant radiotherapy reduces the incidence of local recurrence and may allow for more conservative resections with a reasonable side effect profile.

Proton radiotherapy has been used as an alternative to exenteration in patients with complicated tumors. ${ }^{65}$ This retrospective study examined 20 patients with recurrent and or multifocal or unfavorably located tumors (mostly T2, as per the sixth edition of the TNM staging classification ${ }^{8}$ ) that were not eligible for brachytherapy. Of these, 6 of 20 patients (30\%) had recurrent disease, with two being outside the irradiated field, 2 of 20 patients (10\%) required exenteration, 6 of 20 patients $(30 \%)$ had metastatic disease, and 4 of 20 patients $(20 \%)$ died at the end of follow-up (median followup of 34 months). Side effects included sicca syndrome (19 of 20 patients [95\%]), focal cataract (7 of 20 patients [35\%]), and local eyelash loss in all cases in which the lid was irradiated. Extended statistical evaluation regarding the safety and effectiveness of proton radiotherapy could not be performed, as the sample size was small and follow-up was limited; however, with further study, proton radiotherapy may be an alternative treatment option in specific cases.

\section{Adjuvant therapy: additional adjuvant techniques}

Carbon dioxide laser has been reported to be useful as an adjuvant therapy for large, thin, flat diffuse proliferative lesions with minimal scarring and damage to surrounding ocular structures, although the evidence is limited. ${ }^{66}$ Recombinant interferon-alpha $2 b$ (IFN- $\alpha 2 b$ ) has been used successfully in the treatment of other cancers and is thought to act via an indirect effect on immune regulation rather than directly affecting the tumor. ${ }^{67}$ Two small interventional case series using IFN- $\alpha 2 b$ to treat melanocytic lesions have been published: one a prospective, non-randomized study of nine patients with histologically proven PAM with atypia or $\mathrm{CM}^{68}$ and the other, a retrospective series of five patients with $\mathrm{CM} .{ }^{67}$ In both studies, all but one of the patients had prior initial management of excisional or incisional biopsy and cautery or cryotherapy, following which adjuvant topical recombinant IFN- $\alpha 2 b$ was used. All cases reported in the second study had advanced disease with either extension onto the cornea (T2 N0 $\mathrm{M} 0$, as per the sixth edition of the TNM staging classifica- 
tion $\left.^{8}\right)(n=3)$ or forniceal, palpebral conjunctiva, or caruncle involvement (T3 N0 M0, as per the sixth edition of the TNM staging classification $\left.{ }^{8}\right)(\mathrm{n}=2) .{ }^{67}$ The treatment regimen was different in each study. At a mean follow-up of 24.8 months ${ }^{68}$ and 15 months ${ }^{67}$ for the first and second studies, respectively, both studies reported complete clinical regression in all but one patient, with no systemic side effects. Local ocular side effects were transient and reversible with cessation of treatment. In the first series, ${ }^{68}$ patients had one cycle of treatment for 6 weeks, compared with 3 months of treatment in the second study.$^{67}$ In the first study, ${ }^{68} 5$ patients required more than one cycle to achieve regression, with one patient requiring four cycles and further surgery for stable regression. Further study is required to determine the most effective treatment regimen. IFN- $\alpha 2 b$ was shown to be effective for the treatment of recurrent disease, for use as adjuvant therapy, and for use in patients not able to tolerate MMC.

\section{SLNB}

The role of SLNB in the management of CM remains controversial. The frequency of regional lymph node metastases is reported to be between $26 \%$ and $40 \%,{ }^{69}$ although not all metastatic disease is preceded by regional lymph node metastases. Two studies reported that 17 of 194 patients $(8.7 \%)^{18}$ and 7 of 27 patients $(26 \%)^{15}$ presented with distant metastases without prior or concurrent regional lymph node involvement (skipping metastases). The idea that initial regional metastatic disease is an indication of clinically undetectable systemic spread has been expressed by some, with initial regional lymph node metastases associated with a better prognosis than initial systemic metastatic disease (30 months versus 8 months, respectively; $P=0.012) .{ }^{16} \mathrm{~A}$ few studies show supporting evidence for the use of SLNB for tumors thicker than $2 \mathrm{~mm},{ }^{9,11,16,18,21}$ as well as for tumors greater than $10 \mathrm{~mm}$ in diameter, ${ }^{18}$ with increasing tumor diameter associated with a higher risk of distant recurrence $(P<0.001) .{ }^{18}$ Another study reported that systemic metastatic disease was statistically higher for tumors thicker than $2 \mathrm{~mm}$ (28\% versus $6 \%$ for $\geq 2$ and $>2 \mathrm{~mm}$, respectively; $P=0.026$ ) and for nonlimbal tumors $38 \%$ versus $7 \%$ for nonlimbal versus limbal tumors respectively, $P=$ $0.00023 .{ }^{16}$ Thus, it is thought that for these patients, SLNB may be of prognostic value, identifying micrometastatic disease in regional lymph nodes and allowing for earlier treatment, and hopefully improved survival outcomes..$^{70,71}$

SLNB has also been shown to be useful in detecting regional nodal disease not found on clinical examination or preoperative imaging, including positron emission tomography scans, decreasing the morbidity of prophylactic neck dissections. ${ }^{72,73}$ Furthermore, in patients with only regional metastatic disease, survival of more than 15 years following local treatment has been reported. ${ }^{18}$ These reported long survival times without detectable metastatic disease provide support for a strategy of active clinical search for regional metastases, with subsequent management when detected.

A formal lymph node dissection is recommended if the sentinel lymph node is positive, ${ }^{69}$ with parotidectomy if the parotid basin is involved. ${ }^{74} \mathrm{~A}$ false negative rate of $4 \%$ has been reported, with in transit metastases at the time of the procedure and with histopathology techniques including staining and serial sectioning thought to account for this. Increased use of immunohistochemistry and polymerase chain reaction may increase sensitivity. ${ }^{69}$

The relationship between tumor thickness and sentinel lymph node status was examined in a study of 30 patients with conjunctival or eyelid melanoma who underwent SLNB. ${ }^{74}$ Of the patients with negative SLNB (25 of $30[83 \%]$ ), the mean tumor thickness was $2.57 \mathrm{~mm}$ (range, 0.62-12 $\mathrm{mm}$ ) compared with a mean thickness of $4.86 \mathrm{~mm}$ (range, $2.0-7.2 \mathrm{~mm}$ ) for patients with positive SLNB (5 of $30[17 \%])(P=0.055)$. Large multicenter trials of patients with cutaneous melanoma and micrometastatic disease at regional lymph nodes have shown a survival benefit for lesions of intermediate thickness (1.2-3.5 mm) compared with those whose regional disease was detected by observation, with tumor thickness shown to be the best

Table 3 Summary of concepts in the current literature: conjunctival melanoma (CM) classification, therapy, and management

\section{Summary of concepts}

- The seventh edition of the tumor node metastasis staging classification ${ }^{34}$ more accurately reflects current knowledge of prognostic factors, and it will hopefully serve to provide consistent and comparable data collection for CM across centers

- Surgical excision alone (ie, without adjuvant therapy) has been shown to be less efficacious for CM, regardless of stage $e^{14,23,55}$

- MMC may be useful as an alternative primary treatment for PAM with atypia and, especially, superficial, diffuse, or multifocal disease ${ }^{61}$ Subepithelial nests and nodular tumors have been noted to be MMCresistant ${ }^{61,62}$

- Adjuvant radiotherapy reduces the incidence of local recurrence and may allow for more conservative resections with a reasonable side effect profile

- There are promising anecdotal data for the use of recombinant interferon-alpha $2 \mathrm{~b}$ as adjuvant therapy, compared with $\mathrm{MMC}$

- Sentinel lymph node biopsy may improve the detection of micrometastatic disease in a select group of patients with tumor thickness $>2 \mathrm{~mm}^{9,11,16,18,21}$ and diameter $>10 \mathrm{~mm},{ }^{18}$ although overall survival benefit is yet to be determined ${ }^{74}$ 
predictor of sentinel lymph node involvement in the setting of cutaneous melanoma. ${ }^{73}$ The similarities between the biological behavior of cutaneous and CM suggests that SLNB may be of prognostic benefit in a select group of patients. ${ }^{70}$ However, there is still debate over the benefit of SLNB in terms of overall survival ${ }^{74}$ and further study is needed.

Complications of SLNB include possible injury to the facial nerve, the theoretical risk of permanent discoloration of periorbital and ocular structures from the injection of blue dye, and radiation exposure to the lens and other intraocular structures. However, lymph scintigraphy used in conjunction with SLNB is a safe procedure, with the radiation dose widely used being much less than that used for lymphatic mapping in other locations or that associated with cataract formation or radiation retinopathy. ${ }^{69,73}$

\section{Conclusion}

The current CM classification, therapy, and management issues outlined in this review are summarized in Table 3. The management of CM has developed and progressed over time because of concerted single-institution efforts to classify tumors and to report their treatments, management, and outcomes. The seventh edition of the TNM staging classification more accurately reflects what is currently known of prognostic factors than the sixth edition. It clarifies the terminology used for $\mathrm{CM}$, and will hopefully serve to provide consistent and comparable data collection for CM across centers. In view of the high risk of local recurrence with $\mathrm{CM}$, there may be an indication for the use of adjuvant therapy regardless of clinical staging, or early in the course of management of selected cases; however, further long-term multicenter studies are required. The use of SLNB and standardized screening protocols for metastatic disease are not currently widely used in clinical practice for $\mathrm{CM}$, but this may have significant benefit in a select group of patients. Prospective multicenter studies with associated correlative research are required to improve the overall management and outcome for CM patients.

\section{Acknowledgment}

This study was supported by the Sydney Foundation for Medical Research (RMC, MCM).

\section{Disclosure}

The authors report no conflicts of interest in this work.

\section{References}

1. Seregard S. Conjunctival melanoma. Surv Ophthalmol. 1998;42(4): 321-350.
2. Isager P, Engholm G, Overgaard J, Storm H. Uveal and conjunctival malignant melanoma in Denmark 1943-1997: observed and relative survival of patients followed through 2002. Ophthalmic Epidemiol. 2006; 13(2):85-96.

3. Vajdic CM, Kricker A, Giblin M, et al. Incidence of ocular melanoma in Australia from 1990 to 1998. Int J Cancer. 2003;105(1):117-122.

4. Triay E, Bergman L, Nilsson B, All-Ericsson C, Seregard S. Time trends in the incidence of conjunctival melanoma in Sweden. Br J Ophthalmol. 2009;93(11):1524-1528.

5. Tuomaala S, Eskelin S, Tarkkanen A, Kivelä T. Population-based assessment of clinical characteristics predicting outcome of conjunctival melanoma in whites. Invest Ophthalmol Vis Sci. 2002;43(11): 3399-3408.

6. Yu GP, Hu DN, McCormick S, Finger PT. Conjunctival melanoma: is it increasing in the United States? Am J Ophthalmol. 2003;135(6): 800-806.

7. Inskip PD, Devesa SS, Fraumeni JF Jr. Trends in the incidence of ocular melanoma in the United States, 1974-1998. Cancer Causes Control. 2003;14(3):251-257.

8. Greene FL, Page DL, Fleming ID, et al, editors. AJCC Cancer Staging Manual, 6th ed. New York: Springer-Verlag; 2002.

9. Paridaens AD, McCartney AC, Minassian DC, Hungerford JL. Orbital exenteration in 95 cases of primary conjunctival malignant melanoma. Br J Ophthalmol. 1994;78(7):520-528.

10. Paridaens AD, Minassian DC, McCartney AC, Hungerford JL. Prognostic factors in primary malignant melanoma of the conjunctiva: a clinicopathological study of 256 cases. Br J Ophthalmol. 1994;78(4): 252-259.

11. Lommatzsch PK, Lommatzsch RE, Kirsch I, Fuhrmann P. Therapeutic outcome of patients suffering from malignant melanomas of the conjunctiva. Br J Ophthalmol. 1990;74(10):615-619.

12. Norregaard JC, Gerner N, Jensen OA, Prause JU. Malignant melanoma of the conjunctiva: occurrence and survival following surgery and radiotherapy in a Danish population. Graefes Arch Clin Exp Ophthalmol. 1996;234(9):569-572.

13. Seregard S, Kock E. Conjunctival malignant melanoma in Sweden 1969-1991. Acta Ophthalmol (Copenh). 1992;70(3):289-296.

14. Werschnik C, Lommatzsch PK. Long-term follow-up of patients with conjunctival melanoma. Am J Clin Oncol. 2002;25(3):248-255.

15. Esmaeli B, Wang X, Youssef A, Gershenwald JE. Patterns of regional and distant metastasis in patients with conjunctival melanoma: experience at a cancer center over four decades. Ophthalmology. 2001; 108(11):2101-2105.

16. Tuomaala S, Kivelïä T. Metastatic pattern and survival in disseminated conjunctival melanoma: implications for sentinel lymph node biopsy. Ophthalmology. 2004;111(4):816-821.

17. Tuomaala S, Toivonen P, Al-Jamal R, Kivelä T. Prognostic significance of histopathology of primary conjunctival melanoma in Caucasians. Curr Eye Res. 2007;32(11):939-952.

18. Missotten GS, Keijser S, De Keizer RJ, De Wolff-Rouendaal D. Conjunctival melanoma in the Netherlands: a nationwide study. Invest Ophthalmol Vis Sci. 2005;46(1):75-82.

19. Isager P, Østerlind A, Engholm G, et al. Uveal and conjunctival malignant melanoma in Denmark, 1943-1997: incidence and validation study. Ophthalmic Epidemiol. 2005;12(4):223-232.

20. Anastassiou G, Heiligenhaus A, Bechrakis N, Bader E, Bornfeld N, Steuhl KP. Prognostic value of clinical and histopathological parameters in conjunctival melanomas: a retrospective study. $\mathrm{Br} J$ Ophthalmol. 2002;86(2):163-167.

21. Bobić-Radovanović A, Latković Z, Marinković J, Radovanović Z. Predictors of survival in malignant melanoma of the conjunctiva: a clinicopathological and follow-up study. Eur J Ophthalmol. 1998;8(1):4-7.

22. Damato B, Coupland SE. An audit of conjunctival melanoma treatment in Liverpool. Eye (Lond). 2009;23(4):801-809.

23. De Potter P, Shields CL, Shields JA, Menduke H. Clinical predictive factors for development of recurrence and metastasis in conjunctival melanoma: a review of 68 cases. Br J Ophthalmol. 1993;77(10):624-630. 
24. Shields CL, Shields JA, Gündüz K, et al. Conjunctival melanoma: risk factors for recurrence, exenteration, metastasis, and death in 150 consecutive patients. Arch Ophthalmol. 2000;118(11):1497-1507.

25. Folberg R, McLean IW, Zimmerman LE. Malignant melanoma of the conjunctiva. Hum Pathol. 1985;16(2):136-143.

26. Karim R, Conway RM. Conservative resection and adjuvant plaque brachytherapy for early-stage conjunctival melanoma. Clin Experiment Ophthalmol. 2011;39(4):293-298.

27. Walsh-Conway N, Conway RM. Plaque brachytherapy for the management of ocular surface malignancies with corneoscleral invasion. Clin Experiment Ophthalmol. 2009;37(6):577-583.

28. Crawford JB. Conjunctival melanomas: prognostic factors; a review and an analysis of a series. Trans Am Ophthalmol Soc. 1980;78:467-502.

29. Anastassiou G, Esser M, Bader E, Steuhl KP, Bornfeld N. Expression of cell adhesion molecules and tumour infiltrating leucocytes in conjunctival melanoma. Melanoma Res. 2004;14(5):381-385.

30. Coleman K, Norris S, Weston A, et al; National Health and Medical Research Council. NHMRC Additional Levels of Evidence and Grades for Recommendations for Developers of Guidelines: Stage 2 Consultation; Early 2008 - End Jun 2009. Canberra, Australia: National Health and Medical Research Council; 2009. Available from: http://www. nhmrc.gov.au/_files_nhmrc/file/guidelines/stage_2_consultation_levels_and_grades.pdf. Accessed August 19, 2010.

31. Folberg R, McLean IW, Zimmerman LE. Primary acquired melanosis of the conjunctiva. Hum Pathol. 1985;16(2):129-135.

32. Jakobiec FA, Folberg R, Iwamoto T. Clinicopathologic characteristics of premalignant and malignant melanocytic lesions of the conjunctiva. Ophthalmology. 1989;96(2):147-166.

33. Damato B, Coupland SE. Conjunctival melanoma and melanosis: a reappraisal of terminology, classification and staging. Clin Experiment Ophthalmol. 2008;36(8):786-795.

34. Edge SB, Byrd DR, Compton CC, editors. AJCC Cancer Staging Manual. 7th ed. New York, NY: Springer; 2010.

35. Harooni H, Schoenfield LR, Singh AD. Current appraisal of conjunctival melanocytic tumors: classification and treatment. Future Oncol. 2011;7(3):435-446.

36. Steuhl KP, Rohrbach JM, Knorr M, Thiel HJ. Significance, specificity, and ultrastructural localization of HMB-45 antigen in pigmented ocular tumors. Ophthalmology. 1993;100(2):208-215.

37. Heegaard S, Jensen OA, Prause JU. Immunohistochemical diagnosis of malignant melanoma of the conjunctiva and uvea: comparison of the novel antibody against melan-A with S100 protein and HMB-45. Melanoma Res. 2000;10(4):350-354.

38. Keijser S, Missotten GS, Bonfrer JM, de Wolff-Rouendaal D, Jager MJ, de Keizer RJ. Immunophenotypic markers to differentiate between benign and malignant melanocytic lesions. Br J Ophthalmol. 2006; 90(2):213-217.

39. Sharara NA, Alexander RA, Luthert PJ, Hungerford JL, Cree IA. Differential immunoreactivity of melanocytic lesions of the conjunctiva. Histopathology. 2001;39(4):426-431.

40. Jakobiec FA, Bhat P, Colby KA. Immunohistochemical studies of conjunctival nevi and melanomas. Arch Ophthalmol. 2010;128(2): 174-183.

41. McDonnell JM, Sun YY, Wagner D. HMB-45 immunohistochemical staining of conjunctival melanocytic lesions. Ophthalmology. 1991; 98(4):453-458.

42. Furusato E, Hidayat AA, Man YG, Auerbach A, Furusato B, Rushing EJ. WT1 and Bcl2 expression in melanocytic lesions of the conjunctiva: an immunohistochemical study of 123 cases. Arch Ophthalmol. 2009; 127(8):964-969.

43. Maly A, Epstein D, Meir K, Pe'er J. Histological criteria for grading of atypia in melanocytic conjunctival lesions. Pathology. 2008;40(7):676-681.

44. Lake SL, Jmor F, Dopierala J, Taktak AF, Coupland SE, Damato BE. Multiplex ligation-dependent probe amplification of conjunctival melanoma reveals common BRAF V600E gene mutation and gene copy number changes. Invest Ophthalmol Vis Sci. 2011;52(8):5598-5604.
45. Gear H, Williams H, Kemp EG, Roberts F. BRAF mutations in conjunctival melanoma. Invest Ophthalmol Vis Sci. 2004;45(8):2484-2488.

46. Spendlove HE, Damato BE, Humphreys J, Barker KT, Hiscott PS, Houlston RS. BRAF mutations are detectable in conjunctival but not uveal melanomas. Melanoma Res. 2004;14(6):449-452.

47. Beadling C, Jacobson-Dunlop E, Hodi FS, et al. KIT gene mutations and copy number in melanoma subtypes. Clin Cancer Res. 2008;14(21): 6821-6828

48. Shields JA, Shields CL, Mashayekhi A, et al. Primary acquired melanosis of the conjunctiva: risks for progression to melanoma in 311 eyes. The 2006 Lorenz E. Zimmerman lecture. Ophthalmology. 2008;115(3): 511-519.e2.

49. Shields CL, Markowitz JS, Belinsky I, et al. Conjunctival melanoma: outcomes based on tumor origin in 382 consecutive cases. Ophthalmology. 2011;118(2):389-395.e2.

50. Heindl LM, Hofmann-Rummelt C, Adler W, et al. Tumor-associated lymphangiogenesis in the development of conjunctival melanoma. Invest Ophthalmol Vis Sci. 2011;52(10):7074-7083.

51. Heindl LM, Hofmann-Rummelt C, Adler W, et al. Prognostic significance of tumor-associated lymphangiogenesis in malignant melanomas of the conjunctiva. Ophthalmology. 2011;118(12):2351-2360.

52. Ho VH, Prager TC, Diwan H, Prieto V, Esmaeli B. Ultrasound biomicroscopy for estimation of tumor thickness for conjunctival melanoma. J Clin Ultrasound. 2007;35(9):533-537.

53. Tuomaala S, Kivelä T. Sentinel lymph node biopsy guidelines for conjunctival melanoma. Melanoma Res. 2008;18(3):235.

54. Shields JA, Shields CL, De Potter P. Surgical management of conjunctival tumors. The 1994 Lynn B. McMahan Lecture. Arch Ophthalmol. 1997;115(6):808-815.

55. Damato B, Coupland SE. Management of conjunctival melanoma. Expert Rev Anticancer Ther. 2009;9(9):1227-1239.

56. Shields JA, Shields CL, De Potter P. Surgical management of circumscribed conjunctival melanomas. Ophthal Plast Reconstr Surg. 1998; 14(3):208-215.

57. Tucker SM, Hurwitz JJ, Pavlin CJ, Howarth DJ, Nianiaris N. Scleral melt after cryotherapy for conjunctival melanoma. Ophthalmology. 1993;100(4):574-577.

58. Jakobiec FA, Rini FJ, Fraunfelder FT, Brownstein S. Cryotherapy for conjunctival primary acquired melanosis and malignant melanoma: experience with 62 cases. Ophthalmology. 1988;95(8):1058-1070.

59. Chalasani R, Giblin M, Conway RM. Role of topical chemotherapy for primary acquired melanosis and malignant melanoma of the conjunctiva and cornea: review of the evidence and recommendations for treatment. Clin Experiment Ophthalmol. 2006;34(7):708-714.

60. Wilson MW, Czechonska G, Finger PT, Rausen A, Hooper ME, Haik BG. Chemotherapy for eye cancer. Surv Ophthalmol. 2001;45(5): 416-444.

61. Kurli M, Finger PT. Topical mitomycin chemotherapy for conjunctival malignant melanoma and primary acquired melanosis with atypia: 12 years' experience. Graefes Arch Clin Exp Ophthalmol. 2005;243(11): 1108-1114.

62. Finger PT, Czechonska G, Liarikos S. Topical mitomycin C chemotherapy for conjunctival melanoma and PAM with atypia. Br J Ophthalmol. 1998;82(5):476-479.

63. Ditta LC, ShildkrotY, Wilson MW. Outcomes in 15 patients with conjunctival melanoma treated with adjuvant topical mitomycin C: complications and recurrences. Ophthalmology. 2011;118(9):1754-1759.

64. Stannard CE, Sealy GR, Hering ER, Pereira SB, Knowles R, Hill JC. Malignant melanoma of the eyelid and palpebral conjunctiva treated with iodine-125 brachytherapy. Ophthalmology. 2000;107(5): 951-958.

65. Wuestemeyer H, Sauerwein W, Meller D, et al. Proton radiotherapy as an alternative to exenteration in the management of extended conjunctival melanoma. Graefes Arch Clin Exp Ophthalmol. 2006;244(4): 438-446. 
66. Codère F, Brownstein S, Garwood JL, Dresner SC. Carbon dioxide laser treatment of the conjunctiva and the cornea. Ophthalmology. 1988;95(1):37-45.

67. Finger PT, Sedeek RW, Chin KJ. Topical interferon alfa in the treatment of conjunctival melanoma and primary acquired melanosis complex. Am J Ophthalmol. 2008;145(1):124-129.

68. Herold TR, Hintschich C. Interferon alpha for the treatment of melanocytic conjunctival lesions. Graefes Arch Clin Exp Ophthalmol. 2010; 248(1):111-115.

69. Esmaeli B. Advances in the management of malignant tumors of the eyelid and conjunctiva: the role of sentinel lymph node biopsy. Int Ophthalmol Clin. 2002;42(2):151-162.

70. Esmaeli B. Regional lymph node assessment for conjunctival melanoma: sentinel lymph node biopsy and positron emission tomography. $\mathrm{Br} J$ Ophthalmol. 2008;92(4):443-445.
71. Brownstein S. Malignant melanoma of the conjunctiva. Cancer Control. 2004;11(5):310-316.

72. Baroody M, Holds JB, Kokoska MS, Boyd J. Conjunctival melanoma metastasis diagnosed by sentinel lymph node biopsy. Am J Ophthalmol. 2004;137(6):1147-1149.

73. Esmaeli B, Reifler D, Prieto VG, et al. Conjunctival melanoma with a positive sentinel lymph node. Arch Ophthalmol. 2003;121(12): 1779-1783.

74. Savar A, Ross MI, Prieto VG, Ivan D, Kim S, Esmaeli B. Sentinel lymph node biopsy for ocular adnexal melanoma: experience in 30 patients. Ophthalmology. 2009;116(11):2217-2223.
Clinical Ophthalmology

\section{Publish your work in this journal}

Clinical Ophthalmology is an international, peer-reviewed journal covering all subspecialties within ophthalmology. Key topics include: Optometry; Visual science; Pharmacology and drug therapy in eye diseases; Basic Sciences; Primary and Secondary eye care; Patien Safety and Quality of Care Improvements. This journal is indexed on

Submit your manuscript here: http://www.dovepress.com/clinical-ophthalmology-journal

\section{Dovepress}

PubMed Central and CAS, and is the official journal of The Society of Clinical Ophthalmology (SCO). The manuscript management system is completely online and includes a very quick and fair peer-review system, which is all easy to use. Visit http://www.dovepress.com/ testimonials.php to read real quotes from published authors. 